\title{
Heat generated by cutting ice in deep ice-core drilling
}

\author{
Nobuhiko AZUMA, ${ }^{1}$ Ikuo TANABE, ${ }^{1}$ Hideaki MOTOYAMA ${ }^{2}$ \\ ${ }^{1}$ Nagaoka University of Technology, Kamitomioka 1603-1, Nagaoka 940-2188, Japan \\ E-mail: azuma@mech.nagaokaut.ac.jp \\ ${ }^{2}$ National Institute of Polar Research, Kaga 1-9-10, Itabashi-ku, Tokyo 173-8515, Japan
}

\begin{abstract}
In order to understand and solve the 'warm-ice problem' in deep ice-core drilling, we applied the metal-cutting theory to ice and estimated the heat generated during ice coring taking into account the mechanical and thermal properties of the ice and cutters. We found that (1) most of the heat in cutting is generated by shear deformation at the shear plane of ice, and the heat could increase the chip temperature by several degrees; (2) the rake angle of the cutter has more influence on the temperature increase in chips than the barrel rotation speed and penetration pitch; (3) if the cutter is made of a material with larger thermal conductivity, the temperature increase in the chips can be reduced; and (4) if the density of the liquid is less than the density of ice, the cutting chips sink to the bottom and the friction heat generated by the drill head and slush can raise the ambient temperature of the drill head by several degrees.
\end{abstract}

\section{INTRODUCTION}

In deep ice-core drilling, when approaching the bedrock where ice temperature is close to the melting point the mechanical drilling of ice becomes very difficult and unstable, reducing the penetration obtained by single drilling to a few tens of centimetres. This so-called 'warm-ice problem' is the most crucial unresolved issue in deep ice-core drilling. It is considered to result from the fact that near the melting point of ice the refreezing of ice chips, melted partially during cutting, blocks the pathway of chips into the chips chamber (Fig. 1a), or refrozen chips on the cutters (Fig. 1b) hinder subsequent cutting.

One possible way of overcoming this problem is to prevent chips from refreezing using an ethanol-water solution (EWS), which is already being used in North Greenland Icecore Project (NorthGRIP) and European Project for Ice Coring in Antarctica (EPICA) drilling (Augustin and others, $2007 a, b)$. The drawbacks of this method are that ethanol might intrude into the grain boundaries of ice cores and influence the properties of ice, and that the extraction of ice cores from the core barrel at the surface becomes very difficult because the ice melted by EWS refreezes between the ice core and core barrel during the drill's ascent to the surface where the temperature is usually very low.

Another way of approaching the problem is to prevent ice chips from melting by reducing the cutting heat, which would improve the ice-coring performance near the melting point. In metal-cutting technology, this cutting heat has been well studied both theoretically and experimentally. In this paper, we apply the metal-cutting theory to ice and examine the heat generated during coring, taking into account the mechanical and thermal properties of the ice and cutters.

\section{MODEL}

\section{Notation}

b Cutter width $(\mathrm{m})$

$B_{\mathrm{r}} \quad$ Core barrel rotation speed (rpm)

$C_{\mathrm{i}} \quad$ Specific heat of ice $\left(\mathrm{J} \mathrm{kg}^{-1} \mathrm{~K}^{-1}\right)$

$C_{\mathrm{sl}} \quad$ Specific heat of slush $\left(\mathrm{J} \mathrm{kg}^{-1} \mathrm{~K}^{-1}\right)$
$C_{\mathrm{t}} \quad$ Specific heat of cutter $\left(\mathrm{J} \mathrm{kg}^{-1} \mathrm{~K}^{-1}\right)$

$D_{\mathrm{b}} \quad$ Core barrel diameter $(\mathrm{m})$

$f_{1}, f_{2} \quad$ Distribution function of heat

$F_{\mathrm{H}} \quad$ Tangential force $(\mathrm{N})$

$F_{\mathrm{S}} \quad$ Shear force on shear plane $(\mathrm{N})$

$F_{\mathrm{sl}} \quad$ Friction force by rotation of slush column $(\mathrm{N})$

$F_{\mathrm{T}} \quad$ Friction force on rake plane of $\operatorname{cutter}(\mathrm{N})$

$F_{\mathrm{V}} \quad$ Normal force $(\mathrm{N})$

$K_{\mathrm{i}} \quad$ Thermal diffusivity of ice $\left(\mathrm{m}^{2} \mathrm{~s}^{-1}\right)$

$K_{\mathrm{t}} \quad$ Thermal diffusivity of cutter $\left(\mathrm{m}^{2} \mathrm{~s}^{-1}\right)$

$L \quad$ Contact length $(\mathrm{m})$

$N_{S} \quad$ Normal force on shear plane $(\mathrm{N})$

$N_{\mathrm{T}} \quad$ Normal force on rake plane of $\operatorname{cutter}(\mathrm{N})$

$P_{\mathrm{s}} \quad$ Increment of hydrostatic pressure caused by cutting force $(\mathrm{Pa})$

$p_{\mathrm{t}} \quad$ Pitch of penetration $(\mathrm{m})\left(p_{\mathrm{t}}=3 t_{1}\right)$

$Q_{\mathrm{f}} \quad$ Heat generated on rake plane per unit time $(\mathrm{W})$

$Q_{S} \quad$ Heat generated in shear zone per unit time (W)

$R \quad$ Resultant cutting force $(\mathrm{N})$

$R_{\mathrm{C}} \quad$ Ratio of heat flow into chip

$R_{\mathrm{t}} \quad$ Ratio of heat flow into cutter

$R_{\mathrm{i}} \quad$ Ratio of heat flow into ice body

$S \quad$ Shape function of chip

$T \quad$ Ambient temperature $\left({ }^{\circ} \mathrm{C}\right)$

$T_{\mathrm{c}} \quad$ Chip temperature

$T_{\mathrm{m}} \quad$ Melting temperature of ice $\left({ }^{\circ} \mathrm{C}\right)$

$t_{1} \quad$ Cutting depth (m)

$t_{2} \quad$ Chip thickness (m)

$V \quad$ Cutting velocity $\left(\mathrm{m} \mathrm{s}^{-1}\right)$

$V_{\mathrm{C}} \quad$ Chip velocity $\left(\mathrm{m} \mathrm{s}^{-1}\right)$

$V_{\mathrm{S}} \quad$ Shear velocity on shear plane $\left(\mathrm{m} \mathrm{s}^{-1}\right)$

$W \quad$ Power consumed during cutting (W)

$W_{\mathrm{sl}} \quad$ Friction heat per unit time by rotation of slush column (W)

$\alpha \quad$ Rake angle of cutter $\left(^{\circ}\right)$

$\beta \quad$ Friction angle $\left(^{\circ}\right)$ 


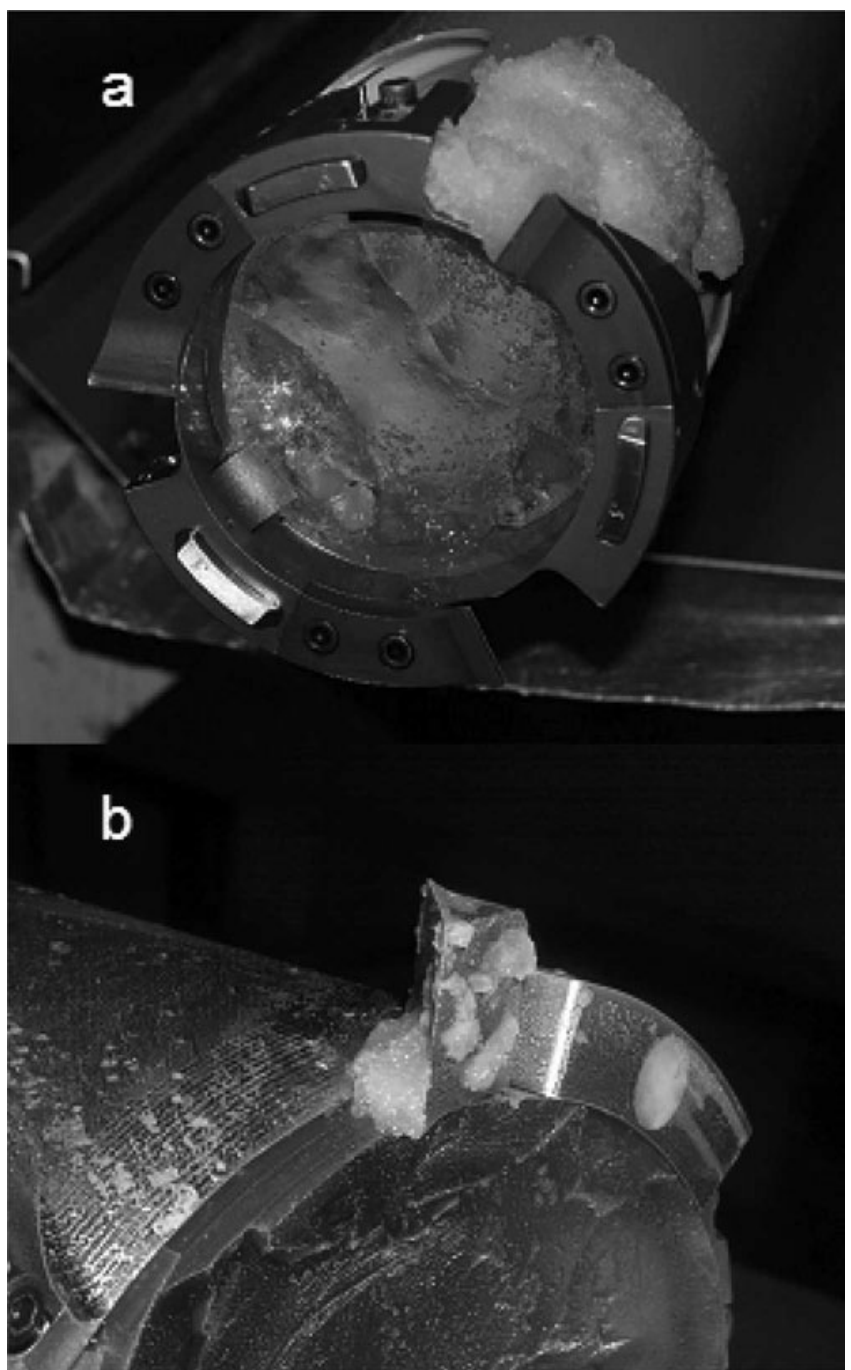

Fig. 1. (a) Refrozen chips blocking the pathway of chips into chips chamber. (b) Refrozen chips on the cutter.

$\gamma_{\mathrm{S}} \quad$ Shear strain of ice $\left(^{*}\right)$

$\Delta T_{\mathrm{c}} \quad$ Temperature increase of chip

$\Delta T_{\mathrm{s}} \quad$ Temperature increase of chip due to shear deformation

$\Delta T_{\mathrm{f}} \quad$ Temperature increase of chip due to friction

$\Delta T_{\mathrm{p}} \quad$ Decrease of melting temperature of ice due to the additional hydrostatic presure by cutting force

$\eta \quad$ Viscosity of slush (Pa s)

$\kappa_{\mathrm{i}} \quad$ Thermal conductivity of ice $\left(\mathrm{W} \mathrm{m}^{-1} \mathrm{~K}^{-1}\right)$

$\kappa_{\mathrm{t}} \quad$ Thermal conductivity of cutter $\left(\mathrm{W} \mathrm{m}^{-1} \mathrm{~K}^{-1}\right)$

$\mu \quad$ Friction coefficient

$\rho_{\mathrm{i}} \quad$ Density of ice $\left(\mathrm{kg} \mathrm{m}^{-3}\right)$

$\rho_{\mathrm{l}} \quad$ Density of slush $\left(\mathrm{kg} \mathrm{m}^{-3}\right)$

$\rho_{\mathrm{t}} \quad$ Density of cutter $\left(\mathrm{kg} \mathrm{m}^{-3}\right)$

$\tau_{\mathrm{c}} \quad$ Shear stress on column plane of slush $(\mathrm{Pa})$

$\tau_{\mathrm{S}} \quad$ Shear stress on shear plane $(\mathrm{Pa})$

$\phi \quad$ Shear angle $\left({ }^{\circ}\right)$

\section{Forces during cutting}

We consider the forces between the ice and each cutter and ice deformation when the cutters of the ice-core drill are cutting ice. Figure 2 shows the force balance between the

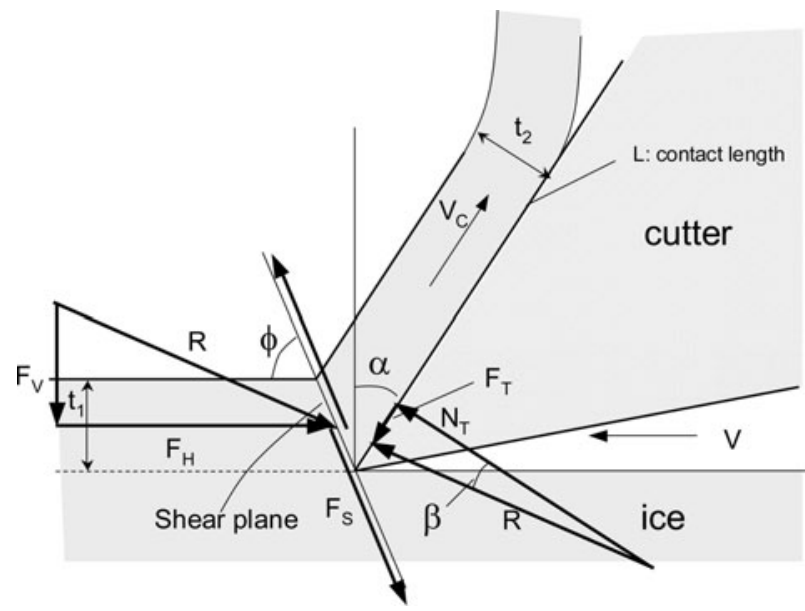

Fig. 2. Force balance between ice and cutter.

ice and a cutter. With respect to the cutter, the friction force on the rake plane $F_{\mathrm{T}}$, the normal force on the rake plane $N_{\mathrm{T}}$, the shear force on the shear plane $F_{\mathrm{S}}$ and the normal force on the shear plane $N_{\mathrm{S}}$ can be expressed as

$$
\begin{aligned}
& F_{\mathrm{T}}=F_{\mathrm{V}} \cos \alpha-F_{\mathrm{H}} \sin \alpha, \\
& N_{\mathrm{T}}=F_{\mathrm{V}} \sin \alpha+F_{\mathrm{H}} \cos \alpha, \\
& F_{\mathrm{S}}=F_{\mathrm{H}} \cos \phi+F_{\mathrm{V}} \sin \phi, \\
& N_{\mathrm{S}}=F_{\mathrm{H}} \sin \phi-F_{\mathrm{V}} \cos \phi,
\end{aligned}
$$

where $F_{\mathrm{V}}$ is the normal force on the ice plane, $F_{\mathrm{H}}$ is the tangential force, $\alpha$ is the rake angle of the cutter and $\phi$ is the shear angle. Here, $F_{\mathrm{V}}, F_{\mathrm{H}}$ and the resultant cutting force $R$ can be expressed as

$$
\begin{gathered}
F_{\mathrm{V}}=\frac{\tau_{\mathrm{S}} t_{1} b \sin (\beta-\alpha)}{\sin \phi \cos \omega}, \\
F_{\mathrm{H}}=\frac{\tau_{\mathrm{S}} t_{1} b \cos (\beta-\alpha)}{\sin \phi \cos \omega}, \\
R=\frac{\tau_{\mathrm{S}} t_{1} b}{\sin \phi \cos \omega^{\prime}} \\
\omega=\phi+\beta-\alpha=45^{\circ},
\end{gathered}
$$

where $\tau_{\mathrm{S}}$ is the shear stress on the shear plane, $t_{1}$ is the cutting depth, $b$ is the cutting width, $\beta$ is the friction angle and $\omega$ is the angle between the shear plane and $R$. Here we assume that the shear plane coincides with the maximum shear stress plane, which implies $\omega=45^{\circ}$.

The friction coefficient $\mu$ is defined as

$$
\mu=\frac{F_{\mathrm{T}}}{N_{\mathrm{T}}}=\tan \beta .
$$

\section{Heat generated by cutting}

The total heat generated per unit time by cutting is given by the sum of the heat generated by the shear deformation of ice $Q_{\mathrm{s}}$ and the friction heat on the rake plane of the cutter $Q_{\mathrm{f}}$ as follows:

$$
\begin{gathered}
Q=Q_{\mathrm{S}}+Q_{\mathrm{f}}=F_{\mathrm{S}} V_{\mathrm{S}}+F_{\mathrm{T}} V_{\mathrm{C}} \\
V_{\mathrm{S}}=\frac{V \cos \alpha}{\cos (\phi-\alpha)}, \\
V_{\mathrm{C}}=\frac{V \sin \alpha}{\cos (\phi-\alpha)},
\end{gathered}
$$




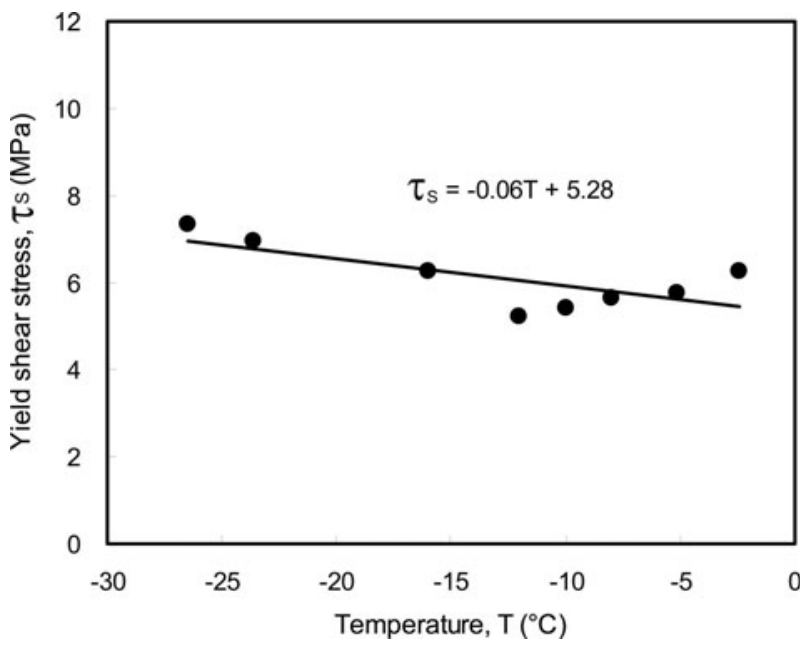

Fig. 3. Yield stress of ice vs temperature Tobtained from Dome Fuji drilling.

where $V_{S}$ is the shear velocity of ice and $V_{C}$ is the chip velocity. Here $V$ is the cutting velocity, as shown in Figure 2, and can be expressed as

$$
V=\pi D_{\mathrm{b}} B_{\mathrm{r}}
$$

where $D_{\mathrm{b}}$ is the core barrel diameter and $B_{\mathrm{r}}$ is the barrel rotation speed.

Assuming that a ratio $\left(f_{1}\right)$ of the heat generated at the shear zone flows into the chip and a ratio $\left(f_{2}\right)$ of the friction heat generated at the rake plane of the cutter flows into the chip, the ratio of the heat that flows into the chip $\left(R_{\mathrm{c}}\right)$, cutter $\left(R_{\mathrm{t}}\right)$ and ice body $\left(R_{\mathrm{i}}\right)$ to the total heat generated can be expressed as

$$
\begin{gathered}
R_{\mathrm{C}}=\frac{f_{1} Q_{\mathrm{s}}+f_{2} Q_{\mathrm{f}}}{Q}, \\
R_{\mathrm{t}}=\frac{\left(1-f_{2}\right) Q_{\mathrm{f}}}{Q}, \\
R_{\mathrm{i}}=\frac{\left(1-f_{1}\right) Q_{\mathrm{S}}}{Q} .
\end{gathered}
$$

The temperature increase in the chip due to shear deformation $\Delta T_{\mathrm{S}}$ can be expressed as

$$
\Delta T_{\mathrm{S}}=\frac{f_{1} \tau_{\mathrm{S}} V_{\mathrm{S}}}{C_{\mathrm{i}} \rho_{\mathrm{i}} V \sin \phi}=\frac{f_{1} \tau_{\mathrm{S}} \cos \alpha}{C_{\mathrm{i}} \rho_{\mathrm{i}} \cos (\phi-\alpha) \sin \phi},
$$

where $C_{\mathrm{i}}$ is the specific heat of ice and $\rho_{\mathrm{i}}$ is the density of ice. With regard to the chip, Equation (17) yields the mean temperature rise of the shear plane in terms of the unknown $f_{1}$. The same temperature rise is given in the work-piece (ice body) in the vicinity of the shear plane. Loewen and Shaw (1954) developed a solution for this workpiece temperature rise using Jaeger's solution (Jaeger, 1942) for the mean temperature at the interface of a perfectly insulated slider moving across a conducting surface with velocity $V$ as heat is continuously and uniformly supplied to the interface; they obtained the following expression for $f_{1}$ :

$$
f_{1}=\frac{1}{1+0.663 \gamma_{\mathrm{S}} /{\sqrt{V \gamma_{\mathrm{S}} t_{1} / 4 K_{i}}}^{\prime}},
$$

where $\gamma_{\mathrm{S}}$ is the shear strain at the shear plane and $K_{\mathrm{i}}$ is the thermal diffusivity of the work-piece material.

As for the temperature rise at the rake plane of the cutter, the friction between the chip and the cutter can be regarded
Table 1. Dataset of ice-core drilling at Dome Fuji to estimate the yield shear stress of ice for drilling

\begin{tabular}{lccccc}
\hline$\alpha$ & $\begin{array}{c}B_{\mathrm{r}} \\
\mathrm{rpm}\end{array}$ & $\begin{array}{c}t_{1} \\
\mathrm{~mm}\end{array}$ & $\begin{array}{c}T \\
{ }^{\circ} \mathrm{C}\end{array}$ & $\begin{array}{c}W \\
\mathrm{~W}\end{array}$ & $\begin{array}{c}\tau_{\mathrm{S}} \\
\mathrm{MPa}\end{array}$ \\
\hline 40 & 50 & 1.17 & -27 & 159 & 7.3 \\
40 & 55 & 1.23 & -24 & 172 & 6.9 \\
40 & 53 & 1.23 & -16 & 147 & 6.2 \\
40 & 51 & 1.33 & -12 & 126 & 5.2 \\
40 & 50 & 1.33 & -10 & 128 & 5.4 \\
40 & 52 & 1.37 & -8 & 140 & 5.6 \\
40 & 52 & 1.40 & -5 & 147 & 5.8 \\
40 & 50 & 1.30 & -2 & 140 & 6.2 \\
\hline
\end{tabular}

as a heat source moving in relation to the chip, and at the same time stationary in relation to the cutter. The following solutions to the temperature increase in the chip because of friction $\Delta T_{\mathrm{f}}$ were developed by Loewen and Shaw (1954):

$$
\begin{gathered}
\Delta T_{\mathrm{f}}=\frac{0.754 f_{2} F_{\mathrm{T}} V_{\mathrm{C}}}{b \kappa_{\mathrm{i}} \sqrt{V_{\mathrm{C}} L / K_{\mathrm{i}}}} \\
f_{2}=\frac{b L\left(S F_{\mathrm{T}} V_{\mathrm{C}} / 2 \kappa_{\mathrm{t}} L-\Delta T_{\mathrm{S}}\right)}{F_{\mathrm{T}} V_{\mathrm{C}}\left(0.377 L / \kappa_{\mathrm{i}} \sqrt{V_{\mathrm{C}} L / 4 K_{\mathrm{i}}}+b S / 2 \kappa_{\mathrm{t}}\right)} \\
S=\frac{2}{\pi}\left\{\frac{2 L}{b} \sinh ^{-1} \frac{b}{2 L}+\sinh ^{-1} \frac{2 L}{b}+\frac{b}{6 L}+\frac{1}{3}\left(\frac{b}{2 L}\right)^{2}\right. \\
\left.-\frac{1}{3}\left[\left(\frac{2 L}{b}\right)^{2}+\sqrt{1+\left(\frac{b}{2 L}\right)^{2}}\right]\right\} .
\end{gathered}
$$

These solutions are well known in metal cutting and continue to be used as a good approximation. Using these equations, we calculated the total temperature increase in the chips due to the heat generated because of cutting:

$$
\Delta T_{\mathrm{C}}=\Delta T_{\mathrm{S}}+\Delta T_{\mathrm{f}}
$$

\section{RESULTS AND DISCUSSION}

Friction coefficient $\mu$ and yield shear stress $\tau_{\mathbf{S}}$ of ice In order to calculate the heat generated by cutting as described above, we need to determine the values of $\mu$ and $\tau_{\mathrm{S}}$. The friction coefficient between ice and steel (cutter) depends on the temperature and the relative velocity between them. Evans and others (1976) studied the variation in the friction coefficient for various temperatures and velocities and found that the friction coefficient between ice and steel was proportional to the difference between the ambient temperature and the melting temperature and proportional to $-1 / 2$ power of the velocity. Based on these experimental results, we derived the following equation which yields the friction coefficient between the ice and the cutter:

$$
\left.\mu=0.0019\left(T_{\mathrm{m}}-T\right) V_{\mathrm{C}}^{-\frac{1}{2}}+0.007\right),
$$

where $T_{\mathrm{m}}\left({ }^{\circ} \mathrm{C}\right)$ is the melting temperature of ice, $T\left({ }^{\circ} \mathrm{C}\right)$ is the ambient temperature and $V_{\mathrm{C}}\left(\mathrm{m} \mathrm{s}^{-1}\right)$ is the chip velocity.

The $\tau_{\mathrm{S}}$ value for high-speed deformation such as ice-core drilling is not yet known, so we estimated it from ice-core drilling data at Dome Fuji, Antarctica. Using Equations (6) 

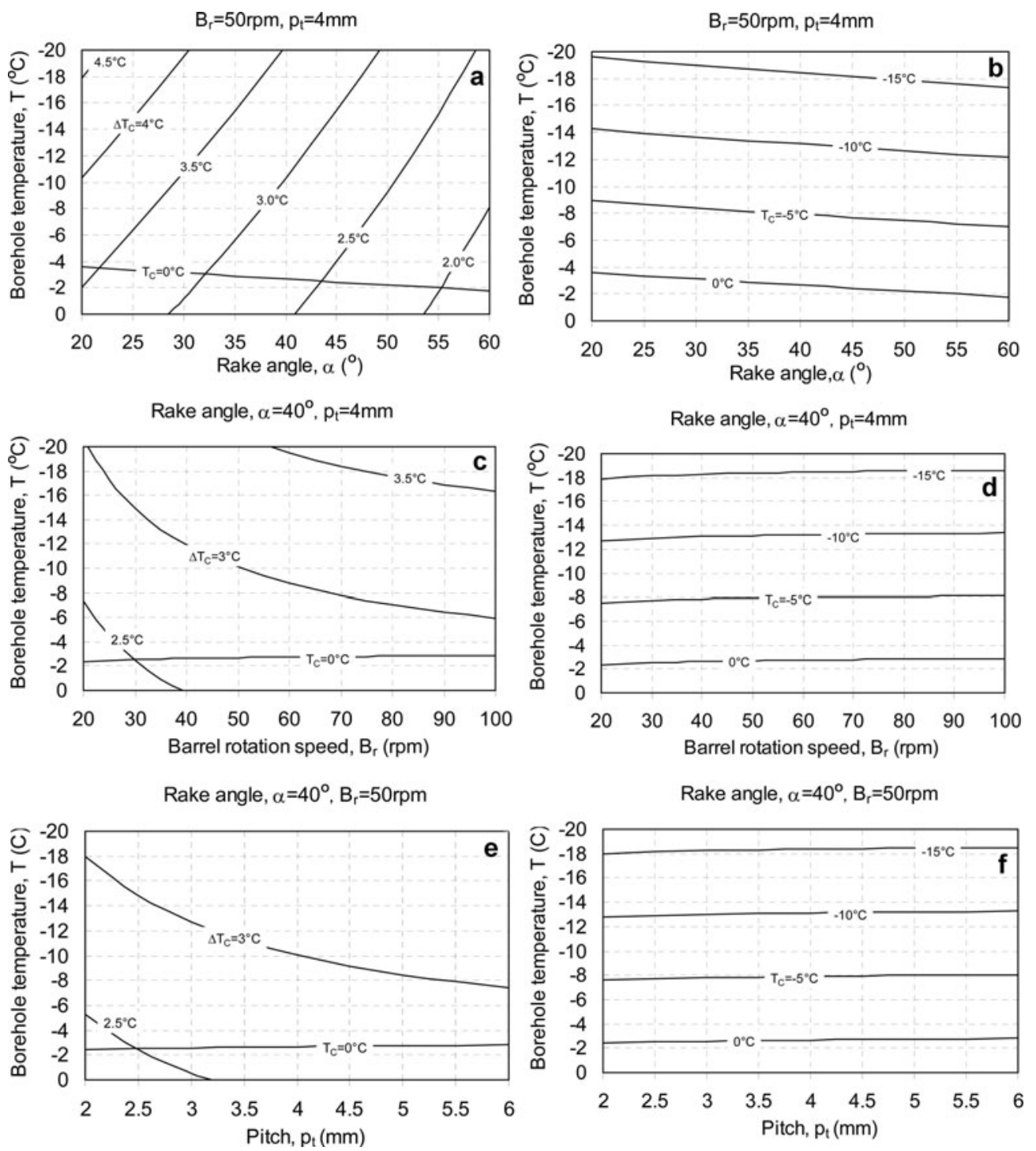

Fig. 4. Temperature increase $\Delta T_{\mathrm{c}}$ of chips (a, c, e) due to heat generation by cutting and the resulting chip temperature (b, $\left.d, f\right)$ calculated for various conditions with ambient (borehole) temperature $T$, barrel rotation speed $B_{\mathrm{r}}$, penetration pitch $p_{\mathrm{t}}\left(=3 t_{1}\right)$ and rake angle of cutter $\alpha$.

and (13), the power consumed for cutting can be written as

$$
W=3 F_{\mathrm{H}} V=\frac{3 \tau_{\mathrm{S}} t_{1} b \cos (\beta-\alpha)}{\sin \phi \cos \omega} \pi D_{\mathrm{b}} B_{\mathrm{r}} .
$$

Here $W$ for cutting was estimated from the difference in the drill motor power used before and after cutting started. In this calculation, we assumed that the motor efficiency is $70 \%$, although this value changes with torque. As listed in Table 1, with each dataset of $\alpha, B_{\mathrm{r}}, t_{1}, T$ and $W$, the $\tau_{\mathrm{S}}$ value was calculated using Equations (8), (9), (12), (13), (23) and (24). The cutter width $b$ was $20 \mathrm{~mm}$ and the core barrel diameter $D_{\mathrm{b}}$ was $94 \mathrm{~mm}$.

Figure 3 shows the $\tau_{\mathrm{S}}$ vs $T$ plot obtained using the Dome Fuji drilling data. It has been reported that during the highspeed deformation of ice $\left(\mathrm{d} \gamma / \mathrm{d} t>10^{-4} \mathrm{~s}^{-1}\right)$ under unconfined pressures, the yield strength of ice depends on neither the temperature nor the strain rate, and the maximum value of $\tau_{\mathrm{S}}$ is $10 \mathrm{MPa}$ (Gold, 1977). Talalay (2003) reported experimental results on the cutting force of the Russian drill KEMS112. According to his results, the yield strength of ice is close to the present estimation obtained from the Dome Fuji drilling data. Although the hydrostatic pressure might slightly increase the yield strength (Jones, 1982) as compared to the unconfined test results, the present estimation from the drilling data shows the same order of yield strength and slight temperature dependence. Based on this result, we use the following equation to determine $\tau_{\mathrm{S}}$ in the equations to calculate the cutting heat:

$$
\tau_{\mathrm{S}}=-0.06 T+5.28,
$$

where $\tau_{\mathrm{S}}$ is in $\mathrm{MPa}$ and $T$ is in ${ }^{\circ} \mathrm{C}$.

Each value of the parameter used in this calculation is listed in Table 2. The yield strength of ice depends on the grain size, crystal orientation, impurity content and so on. We do not take these effects into account in the present study because no detailed study has been performed taking into account these parameters in the high-speed deformation regime.

\section{Chip temperature increase due to cutting}

Figure 4 shows the values of $\Delta T_{\mathrm{C}}$ for the chips (Fig. $4 \mathrm{a}$, C and e) due to the heat generated by cutting, and the resulting chip temperature (Fig. $4 b, d$ and f) calculated for various conditions of ambient (borehole) temperature $T$, barrel rotation speed $B_{\mathrm{r}}$, penetration pitch $p_{\mathrm{t}}\left(=3 t_{1}\right)$ and rake angle of the cutter $\alpha$. In this figure, if we take into account the 


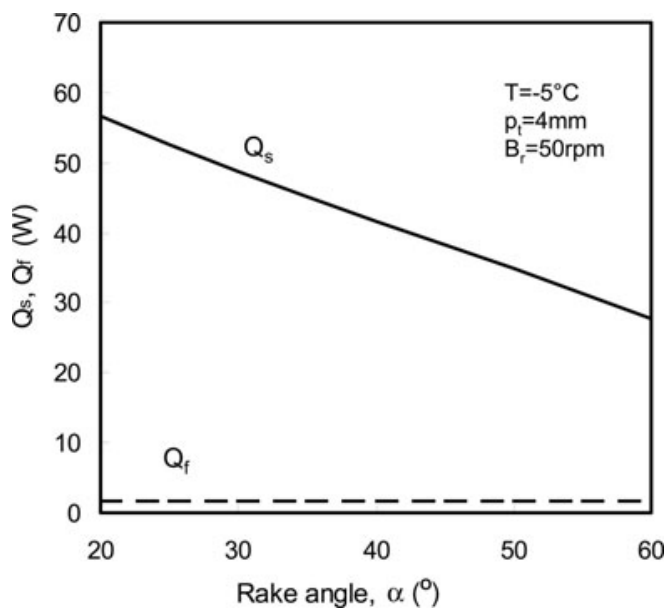

Fig. 5. Comparison of $Q_{\mathrm{s}}$ (heat by shear deformation) and $Q_{\mathrm{f}}$ (heat by friction) for various $\alpha$ values at $T=-5^{\circ} \mathrm{C}, p_{\mathrm{t}}=4 \mathrm{~mm}$ and $B_{\mathrm{r}}=$ $50 \mathrm{rpm}$.

decrease in the pressure-melting point due to the hydrostatic pressure, the melting-point line should be $T_{\mathrm{C}}=-2$ to $-3^{\circ} \mathrm{C}$ for a depth of $3000 \mathrm{~m}$. The value of $\alpha$ has more influence on the temperature increase of chips than $B_{\mathrm{r}}$ and $p_{\mathrm{t}}$, and this increase in chip temperature becomes $2-4^{\circ} \mathrm{C}$ under the condition that is commonly employed in polar deep ice drillings. This means that if the borehole temperature is approximately $-5^{\circ} \mathrm{C}$ at $3000 \mathrm{~m}$ depth, the cutting chips should almost melt because of the cutting heat. This result is in very good agreement with the fact that the warm-ice problem is observed above a temperature of $-5^{\circ} \mathrm{C}$ (Augustin and others, 2007a, b).

On the other hand, the pressure-melting point decrease due to the additional hydrostatic pressure $P_{\mathrm{s}}$ at the shear zone produced by $R$ should also be taken into account in this problem involving the melting of chips. This amount of temperature decrease $\Delta T_{\mathrm{p}}$ is given by

$$
\Delta T_{\mathrm{p}}=\frac{\mathrm{d} T}{\mathrm{~d} p} P_{\mathrm{s}}=0.074 \times \frac{1}{3} \frac{R \cos (\beta-\alpha)}{t_{1} b} .
$$

If $p_{\mathrm{t}}$ is $4 \mathrm{~mm}, \alpha$ is $40^{\circ} \mathrm{C}$ and $B_{\mathrm{r}}$ is $50 \mathrm{rpm}$, then $\Delta T_{\mathrm{p}}$ is only $0.15^{\circ} \mathrm{C}$. (In this calculation, we used the value of $\mathrm{d} T / \mathrm{d} p$ $\left(0.074 \mathrm{KMPa}^{-1}\right)$ for pure water as the Clausius-Clapeyron constant. If we use the value for air-saturated water $\left(0.098 \mathrm{KMPa}^{-1}\right), \Delta T_{\mathrm{p}}$ becomes $0.20^{\circ} \mathrm{C}$.) Therefore this contribution to chip melting is very small compared to the heat generated because of cutting.

\section{Heat source and sink in cutting}

As shown in Equation (10), the heat generated by cutting is the sum of the contribution from shear deformation of ice $Q_{\mathrm{s}}$ and the contribution from friction on the rake plane of the cutter $Q_{\mathrm{f}}$. Figure 5 shows the values of $Q_{\mathrm{s}}$ and $Q_{\mathrm{f}}$ for various

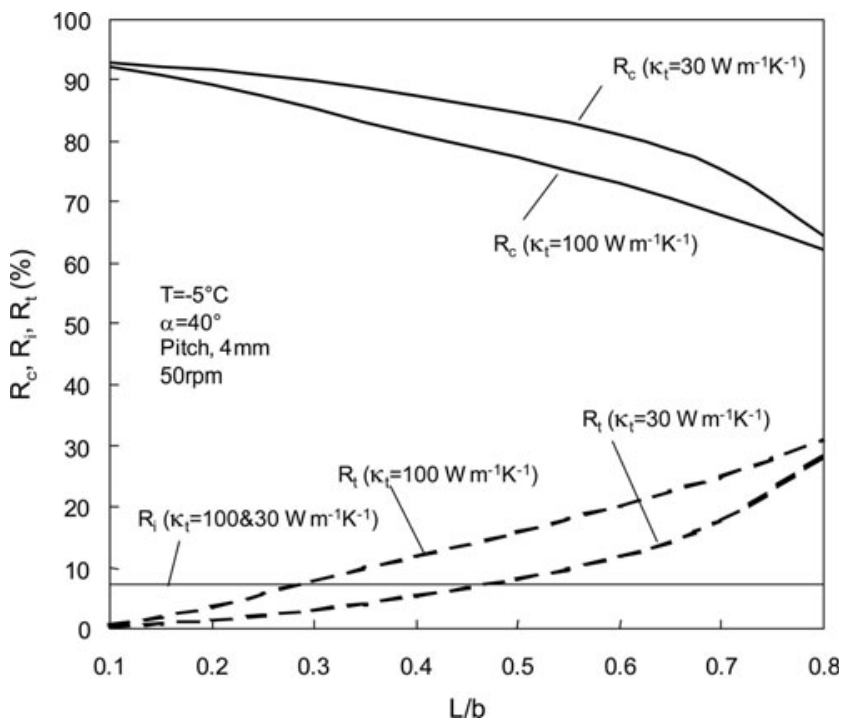

Fig. 6. Ratio of heat flow into the chip $\left(R_{\mathrm{c}}\right)$, cutter $\left(R_{\mathrm{t}}\right)$ and ice body $\left(R_{\mathrm{i}}\right)$ for various values of $L / b$.

values of $\alpha$ at $T=-5^{\circ} \mathrm{C}, p_{\mathrm{t}}=4 \mathrm{~mm}$ and $B_{\mathrm{r}}=50 \mathrm{rpm}$. Most of the heat is contributed by the shear deformation of ice, which can be reduced by increasing $\alpha$. The heat generated by cutting is redistributed to the chips, cutter and ice body. The ratios of the heat flow to the chips and cutter depend on the ratio of the contact length of the chip on the rake plane of the cutter $L$ to the cutter width $b$. Figure 6 shows the ratio of the heat flow into the chip $R_{\mathrm{C}}$, cutter $R_{\mathrm{t}}$ and ice body $R_{\mathrm{i}}$ for various values of $L / b$. The calculations were performed for two different thermal conductivities of the cutter (30 and $100 \mathrm{~W} \mathrm{~m}^{-1} \mathrm{~K}^{-1}$ ). This result shows that a larger contact length and larger thermal conductivity reduce the heat flow into the chips since more heat flows into the cutter. The $\Delta T_{\mathrm{C}}$ values for the chips were calculated for various values of $L$ and the thermal conductivity of the cutter $\kappa_{\mathrm{t}}$ at $T=-5^{\circ} \mathrm{C}, \alpha=40^{\circ}$, $p_{\mathrm{t}}=4 \mathrm{~mm}, B_{\mathrm{r}}=50 \mathrm{rpm}$ and $b=20 \mathrm{~mm}$ (Fig. 7). If the cutter is made of a material with larger thermal conductivity such as ceramics $\left(\sim 100 \mathrm{~W} \mathrm{~m}^{-1} \mathrm{~K}^{-1}\right)$ and a larger contact length $(L / b \sim 1)$, the temperature increase in the chips can be reduced by about $1^{\circ} \mathrm{C}$. However, if hard drilling in warm ice is caused by the refreezing of chips on the cutter, a cutter with low thermal conductivity and a small contact length can help prevent the chips from refreezing on the cutter, as the dissipation of heat from the chips onto the cutter is reduced.

\section{Effect of fluid properties}

Another important issue in the warm-ice problem is the drilling liquid. If the liquid density is smaller than that of the ice, then the cutting chips sink and accumulate at the bottom of the hole. This mixture of chips and liquid (called

Table 2. Values of each parameter used in this study

\begin{tabular}{ccccccccccccc}
\hline $\begin{array}{c}b \\
\mathrm{~mm}\end{array}$ & $\begin{array}{c}\mathrm{mm} \\
\mathrm{mm}\end{array}$ & $\begin{array}{c}D_{\mathrm{b}} \\
\mathrm{mm}\end{array}$ & $\begin{array}{c}C_{\mathrm{i}} \\
\mathrm{J} \mathrm{kg}^{-1} \mathrm{~K}^{-1}\end{array}$ & $\begin{array}{c}\rho_{\mathrm{i}} \\
\mathrm{kg} \mathrm{m}^{-3}\end{array}$ & $\begin{array}{c}\kappa_{\mathrm{i}} \\
\mathrm{W} \mathrm{m}^{-1} \mathrm{~K}^{-1}\end{array}$ & $\begin{array}{c}K_{\mathrm{i}} \\
\mathrm{mm}^{2} \mathrm{~s}^{-1}\end{array}$ & $\begin{array}{c}C_{\mathrm{t}} \\
\mathrm{Jkg}^{-1} \mathrm{~K}^{-1}\end{array}$ & $\begin{array}{c}\rho_{\mathrm{t}} \\
\mathrm{kg} \mathrm{m}^{-3}\end{array}$ & $\begin{array}{c}\kappa_{\mathrm{t}} \\
\mathrm{Wm}^{-1} \mathrm{~K}^{-1}\end{array}$ & $\begin{array}{c}K_{\mathrm{t}} \\
\mathrm{mm}^{2} \mathrm{~s}^{-1}\end{array}$ & $\begin{array}{c}\rho_{\mathrm{sl}} \\
\mathrm{kg} \mathrm{m}^{-3}\end{array}$ & $\begin{array}{c}C_{\mathrm{sl}} \\
\mathrm{Jg}^{-1} \mathrm{~K}^{-1}\end{array}$ \\
\hline 20 & 10 & 94 & 2078 & 920 & 2.29 & 1.20 & 460 & 7800 & 30 & 8.35 & 920 & 2100 \\
\hline
\end{tabular}




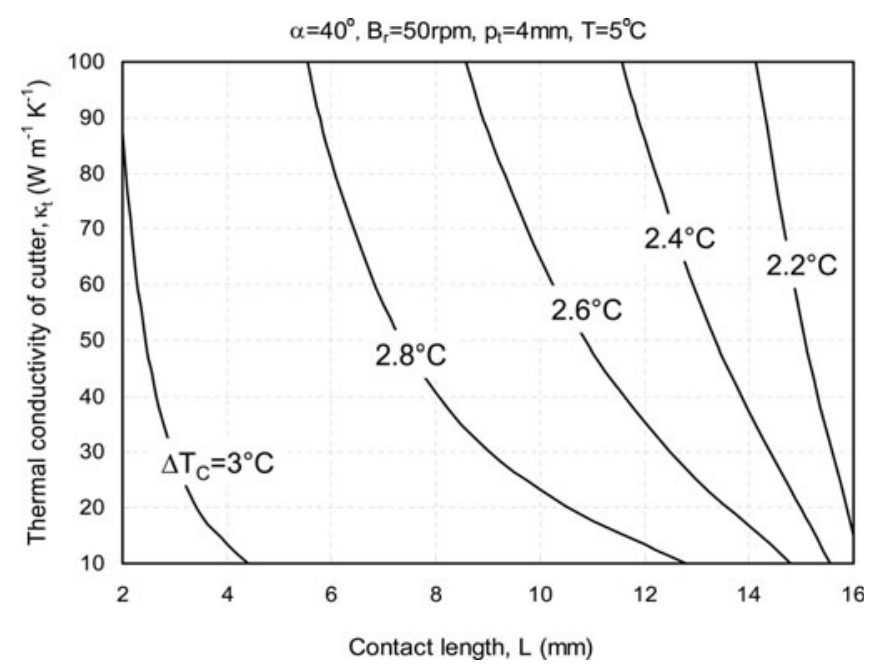

Fig. 7. $\Delta T_{\mathrm{c}}$ of chips for various contact lengths $L$ and thermal conductivities of the cutter $\kappa_{\mathrm{t}}$ at $T=-5^{\circ} \mathrm{C}, \alpha=40^{\circ}, p_{\mathrm{t}}=4 \mathrm{~mm}$, $B_{\mathrm{r}}=50 \mathrm{rpm}$ and $b=20 \mathrm{~mm}$.

'slush') produces friction heat between the hole wall and the drill head and raises the ambient temperature around the drill head. Now we examine the temperature increase in the slush, assuming that the space between the hole wall and the drill head is filled with slush from the bottom to height $h$, as shown in Figure 8. If the drill head rotates with a velocity $V$, the shear stress $\tau_{\mathrm{c}}$ on a column plane is

$$
\tau_{\mathrm{c}}=\eta \frac{\mathrm{V}}{\mathrm{b}}
$$

where $\eta$ is the viscosity of the slush and $b$ is the width of the space, i.e. cutter width.

The friction heat generated per unit time by the rotation of this slush column is given by

$$
W_{\mathrm{sl}}=F_{\mathrm{sl}} V=\pi D_{\mathrm{b}} h \tau_{\mathrm{c}} V=\frac{\pi D_{\mathrm{b}} h \eta}{b} V^{2}
$$

The temperature-increasing rate of the slush is

$$
\frac{\mathrm{d} T}{\mathrm{~d} t}=\frac{W_{\mathrm{sl}}}{\pi D_{\mathrm{b}} h b \rho_{\mathrm{sl}} C_{\mathrm{sl}}}=\frac{\eta V^{2}}{b^{2} \rho_{\mathrm{sl}} C_{\mathrm{sl}}},
$$

where $\rho_{\mathrm{sl}}$ is the density of the slush and $C_{\mathrm{sl}}$ is the specific heat of the slush. These values are calculated assuming that

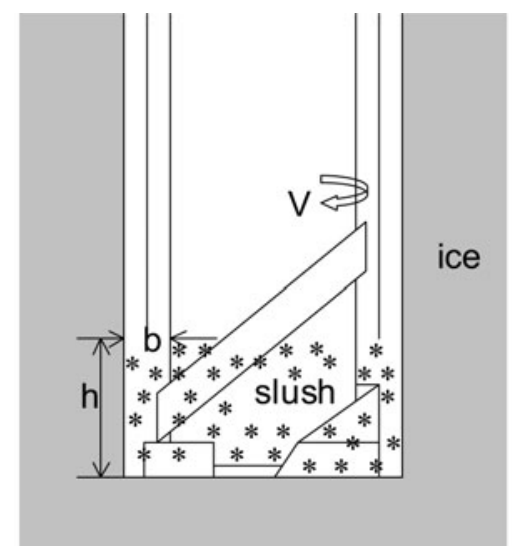

Fig. 8. Schematic diagram of the slush column and drill head at the bottom of the borehole.

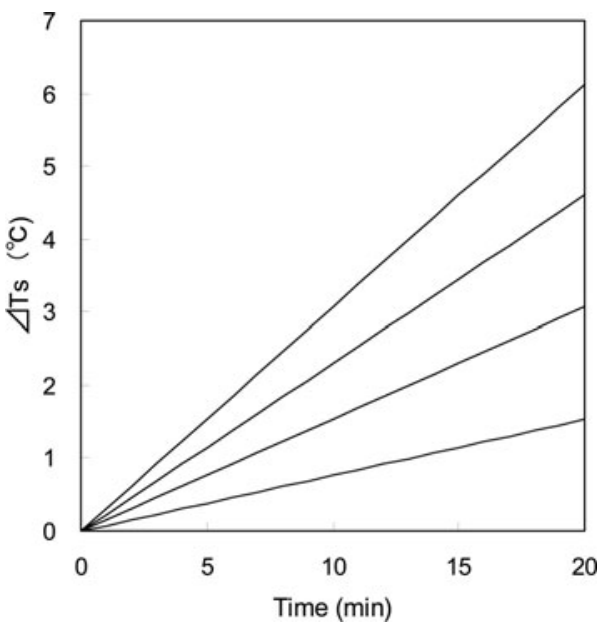

Fig. 9. Temperature increase in the slush with time for various slush viscosities.

$50 \%$ of the slush is made of ice chips and the remaining $50 \%$ of the drilling liquid ( $n$-butyl acetate). Because the viscosity of this slush is unknown, we presume it to be of the order of $10 \mathrm{Pas}$ on the analogy that the slush is made of water and snow (Kobayashi and others, 1994). Figure 9 shows the temperature increase in the slush with time for various viscosities of the slush. This suggests that the friction heat because of the rotation of the slush column could raise the ambient temperature of the drill head by several degrees if the liquid density is less than the ice density and the chips remain at the bottom. This might be considered another bad characteristic of the warm-ice problem.

\section{CONCLUSIONS}

Based on the metal-cutting theory, we examined the heat generated during ice coring and the following conclusions were drawn:

1. Most of the heat during cutting is generated by shear deformation at the shear plane of the ice; this heat raises the chip temperature by several degrees under the condition that is commonly used in polar deep ice drillings.

2. The rake angle has more influence on the temperature increase in chips than the barrel rotation speed and penetration pitch.

3. If the cutter is made of a material with larger thermal conductivity such as ceramics $\left(\sim 100 \mathrm{~W} \mathrm{~m}^{-1} \mathrm{~K}^{-1}\right)$ and a larger contact length $(L / b \sim 1)$, the temperature increase in the chips can be reduced by about $1^{\circ} \mathrm{C}$.

4. The friction heat because of the rotation of the slush column can raise the ambient temperature of the drill head by several degrees if the liquid density is less than the ice density and the chips remain at the bottom.

As shown in Equation (17), the increase in the chip temperature $\Delta T_{\mathrm{C}}$ is proportional to the yield shear stress $\tau_{\mathrm{S}}$. Because the value of $\tau_{\mathrm{S}}$ estimated from the drilling data involves some uncertainty, $\Delta T_{\mathrm{C}}$ might change by a few degrees. In order to precisely estimate $\Delta T_{C}$, it is imperative to conduct laboratory tests to obtain the yield shear stress of 
ice for various temperatures, hydrostatic pressures, cutting speeds, grain sizes, crystal orientations, etc. The present analysis shows that a larger rake angle induces less heat at the shear zone. However, a rake angle greater than approximately $50^{\circ}$ is unrealistic for drilling purposes. Therefore, chips cannot be prevented from melting in the vicinity of the melting point of ice. It is effective to rapidly dissipate the heat generated by shear into the tool section by having a large contact area, with the cutters made from a material having high thermal conductivity because the chips cannot melt immediately at the shear zone. At present, the only effective method of preventing the melted chips from refreezing and blocking the pathway into the chip chamber (which is the main cause of the warm-ice problem) seems to be to inject EWS at the bottom of the hole.

The density of the drilling liquid is another important factor for warm-ice drilling. As shown in Figure 9, if the density of the liquid is less than the density of ice, the cutting chips sink to the bottom and the friction heat generated by the drill head and the slush could raise the ambient temperature of the drill head by a few degrees. We should confirm this problem by laboratory experiments. n-Butyl acetate used at Dome Fuji has a larger density than ice even at $3000 \mathrm{~m}$ depth. This seems to have worked successfully in warm-ice drilling, and drilling progresses without difficulty down to $3000 \mathrm{~m}$ depth, where the hole temperature is about -3 to $-4^{\circ} \mathrm{C}$.

\section{ACKNOWLEDGEMENTS}

We thank R. Greve, J. Schwander, F. Wilhelms and an anonymous reviewer for very helpful comments.

\section{REFERENCES}

Augustin, L. and 6 others. 2007a. Drilling comparison in 'warm ice' and drill design comparison. Ann. Glaciol., 47, 73-78.

Augustin, L., S. Panichi and F. Frascati. 2007b. EPICA Dome C2 drilling operations: performances, difficulties, results. Ann. Glaciol., 47, 68-72.

Evans, D.C.B., J.F. Nye and K.J. Cheeseman. 1976. The kinetic friction of ice. Proc. R. Soc. London, Ser. A, 347(1651), 493-512.

Gold, L.W. 1977. Engineering properties of fresh-water ice. J. Glaciol., 19(81), 197-212.

Jaeger, J.C. 1942. Moving sources of heat and the temperature at sliding contacts. J. Proc. R. Soc. NSW, 76, 203-224.

Jones, S.J. 1982. The confined compressive strength of polycrystalline ice. J. Glaciol., 28(98), 171-177.

Kobayashi, S., K. Izumi and I. Kamiishi. 1994. Slushflow disasters in Japan and its characteristics. In Proceedings of the International Snow Science Workshop, 30 October-4 November 1994, Snowbird, Utah. Snowbird, UT, International Snow Science Workshop, 71-81.

Loewen, E.G. and M.C. Shaw. 1954. On the analysis of cutting-tool temperatures. Trans. ASME, 76, 217-231.

Talalay, P.G. 2003. Power consumption of deep ice electromechanical drills. Cold Reg. Sci. Technol., 37(1), 69-79. 